\title{
Effect of Inorganic lons on Pyrite Catalyzed Fenton Reaction
}

\author{
Marianela Escobar Castillo' ${ }^{1}$, Tarek A. Gad-Allah², Mohamed E. M. Ali², Ahmed Hassan Salem², Ahmed \\ S.G. Khalil ${ }^{3}$, M. Grazia Francesconi ${ }^{4}$, Doru C. Lupascu ${ }^{1}$ \\ ${ }^{1}$ Institute for Material Science and Center for Nanointegration Duisburg-Essen (CENIDE), University of Duisburg-Essen \\ Universtätsstr. 15, 45141 Essen, Germany \\ marianela.escobar@uni-due.de; tareqAbdelshafy@hotmail.com \\ ${ }^{2}$ Water Pollution Research Department, National Research Centre \\ 33 El Bohouth st. P.O. 12622 Dokki, Giza, Egypt \\ ${ }^{3}$ Center for Environmental and Smart Technology \& Physics Department, Fayoum University \\ Fayoum, Egypt \\ ${ }^{4}$ School of Mathematics and Physical Sciences Chemistry, University of Hull \\ Cottingham Road, Hull, HU 6 7R, UK
}

\begin{abstract}
Industrial wastewaters contain not only organic pollutants but also considerable amounts of inorganic ions that may affect the efficiency of wastewater remediation processes. Thus, it is important to study the influence of such ions in the respective chemical reactions. Here we performed Fenton reactions for the decolourization of Rhodamine B dye using the naturally occurring mineral pyrite $\left(\mathrm{FeS}_{2}\right)$ as heterogeneous catalyst in presence of different inorganic ions that are typically present in wastewater. Additionally, the effect of milling time of the pyrite powder on the performance of the heterogeneous Fenton reaction has also been investigated.
\end{abstract}

Keywords: Wastewater Remediation, Heterogeneous Fenton Reaction, Pyrite, Nanoparticles, Inorganic Ions.

\section{Introduction}

Synthetic dyes are among the worst pollutants contaminating rivers and water reserves. A great deal of research is being carried out worldwide to identify low-cost and environmentally friendly approaches to the transformation of such pollutants into less damaging species. Research on advanced oxidation processes (AOPs) is becoming a hot topic more and more, because these approaches are considered to be more efficient than conventional water treatments. More specifically, processes based on the Fenton reaction prove to be superior to physicochemical and biological processes. In the classic Fenton reaction hydroxyl radicals $\left({ }^{\circ} \mathrm{OH}\right)$ are created from the decomposition of hydrogen peroxide $\left(\mathrm{H}_{2} \mathrm{O}_{2}\right)$ induced by aqueous $\mathrm{Fe}^{2+}$-salts. These highly reactive radicals attack the organic pollutant to degrade it into smaller organics molecules or until complete mineralization to carbon dioxide and water [1]. However, the efficiency of this reaction has been put into question many times, due to some disadvantages such as high operation costs, limited optimum $\mathrm{pH}$ range (around $\mathrm{pH} 3$ ), large volume of iron hydroxide $\left(\mathrm{Fe}(\mathrm{OH})_{3}\right)$ produced and difficulties in recycling of the homogeneous catalyst $\left(\mathrm{Fe}^{2+}-\mathrm{salt}\right)$ [1]. On the other hand, the heterogeneous Fenton process in which the source of $\mathrm{Fe}^{2+}$-ions is a solid has been found to be more efficient, because there is a continuous production of $\mathrm{Fe}^{2+}$-aqueous cations from the continuous dissolution of the solid. Solid iron-based catalyst such as iron minerals can be easily recovered after reaction and maintain significant reactivity in successive operations [2].

Pyrite, one of the most abundant iron sulphide mineral on the Earth [3] has been used more recently as a catalyst in Fenton processes for the removal of organic pollutants from water because of its availability, low-cost and environmental compatibility [4-7]. Pyrite can be oxidized under acidic and neutral conditions, resulting in the formation of dissolved $\mathrm{Fe}^{2+}$ -ions (Eq. (1)) [2]. The presence of $\mathrm{H}_{2} \mathrm{O}_{2}$ increases the production of $\mathrm{Fe}^{2+}$-ions (Eq. (2)-(4)) [8]. Moreover, the acidification of the reaction medium is regulated by the generation of $\mathrm{H}^{+}$as shown in Eqs. (1) - (3). This allows for an optimal $\mathrm{pH}$ value ( $\mathrm{pH} 3-4)$ where the precipitation of $\mathrm{Fe}(\mathrm{OH})_{3}$ is avoided.

$\mathrm{FeS}_{2}$ is particularly effective as catalyst when used in the form of nanoparticles [3]. However, the preparation of nanoparticles often requires rather complex synthetic methods. One simple method to obtain nano-sized materials is mechanical ball milling (MBM). By this technique, high mass production can be obtained at ambient temperature in a short 
processing time making this technique appropriate for large-scale production [9, 10]. Pourghahramani et al. [11] have demonstrated that the mechanical milling of pyrite causes not only a change in the crystallite size but also a change of its surface properties like amorphization degree and lattice strain. It is well proven that such changes in a material can improve its reactivity. In a mechanical milled material with small crystallite size and high specific surface area there are a large number of grain boundaries providing more atoms ready to react. In addition, a higher degree of amorphization in the mechanical milled powders implies that the atomic bonds between constituent elements in the material are weakened promoting its reactivity. Another reason for reactivity improvement of the material is the enhancement of the lattice strain due to the mechanical milling process [11].

Very limited research has been done on the preparation of pyrite nanoparticles using MBM and use of it for the degradation of dyes [12]. The effect of prolonged milling, and the effect of inorganic ions like chloride-, nitrate-, sulphate and phosphate ions have not been studied yet.

$$
\begin{gathered}
2 \mathrm{FeS}_{2}+7 \mathrm{O}_{2}+2 \mathrm{H}_{2} \mathrm{O} \rightarrow 2 \mathrm{Fe}^{2+}+4 \mathrm{SO}_{4}^{2-}+4 \mathrm{H}^{+} \\
2 \mathrm{FeS}_{2}+15 \mathrm{H}_{2} \mathrm{O}_{2} \rightarrow 2 \mathrm{Fe}^{3+}+4 \mathrm{SO}_{4}^{2-}+2 \mathrm{H}^{+}+14 \mathrm{H}_{2} \mathrm{O} \\
\mathrm{FeS}_{2}+14 \mathrm{Fe}^{3+}+8 \mathrm{H}_{2} \mathrm{O} \rightarrow 15 \mathrm{Fe}^{2+}+2 \mathrm{SO}_{4}^{2-}+16 \mathrm{H}^{+} \\
\mathrm{Fe}^{2+}+\mathrm{H}_{2} \mathrm{O}_{2} \rightarrow \mathrm{Fe}^{3+}+\mathrm{OH}^{-}+\cdot \mathrm{OH}
\end{gathered}
$$

\section{Experimental}

Mineral pyrite (Alfa Aesar) was first manually ground. Then, mechanical milling was performed at $600 \mathrm{rpm}$ in an ethanol medium (planetary ball mill Retsch PM $100 \mathrm{CM}$ ). Zirconium oxide balls (diameter: 2, 5 and $10 \mathrm{~mm}$ ) were used for milling by balls to powder weight ratio of 10:1. The surface areas of the materials were calculated using the BrunauerEmmett-Teller (BET) equation (COULTER SA 3100). The crystallographic structure of the samples were investigated using a Siemens D5000 $\mathrm{Cu} \mathrm{K} \alpha$ radiation X-ray diffractometer. A scanning electron microscope (SEM, QUANTA 400F EG) and an atomic force microscope (AFM) (MFP-3D Asylum Research) were used to study the morphology of the samples. The Fenton experiments were performed in ambient conditions, under stirring and natural $\mathrm{pH}$. The pyrite powder was suspended in the Rhodamine $\mathrm{B}(\mathrm{RB})$ solution containing inorganic ions. After reaching the adsorption equilibrium, the experiments were initiated by adding $\mathrm{H}_{2} \mathrm{O}_{2} .1 \mathrm{ml}$ samples were withdrawn at pre-determined time intervals during the reaction, and then sodium hydroxide was immediately added to the samples as reaction inhibitor. The samples were then centrifuged and the absorption spectra were measured with a UV-Visible spectrophotometer (Shimadzu UV 2600).

\section{Results and Discussion}

\subsection{Effect of Milling Time}

The initial size of the used mineral pyrite granules was 1.5- $4.8 \mathrm{~mm}$ (technical data Alfa Aesar). The XRD pattern of the manually ground material is consistent with the pure cubic pyrite phase with no significant impurities in the sample (Fig. 1). Analysis of the XRD patterns of the mechanical milled powders indicate that no change in the crystal structure occurred during milling operation (Fig. 1). The SEM images of the samples are shown in Figure 2. The pictures clearly demonstrate an enhancement in the particle homogeneity by increasing the milling time, as well as the presence of nanoparticles in the samples milled for 5, 10 and $24 \mathrm{~h}$. The AFM image for the $24 \mathrm{~h}$ sample (Fig. 2f) confirm the presence of nanoparticles in the powder. Specific surface areas of the $\mathrm{FeS}_{2}$ catalysts ball-milled for times between 0 and 24 hours were obtained via BET measurements and are shown in Table 1. The data show an increase in the specific surface area as the ball-milling time increase and, noticeably, a substantial increase of the specific surface area for the catalyst ball-milled for 24 hours $\left(17.1 \mathrm{~m}^{2} / \mathrm{g}\right)$ in comparison to the one ball-milled for 10 hours $\left(7.3 \mathrm{~m}^{2} / \mathrm{g}\right)$. The powder ball-milled for 24 hours (Fig.2e and 2f) showed the highest surface area.

Fig. 3 shows the decolourization of Rhodamine B (RB) using $\mathrm{FeS}_{2}$ catalysts ball-milled for different times, demonstrating the effect of milling time on the decolourization efficiency of the heterogeneous Fenton reaction. The use of pyrite powder as catalyst acidified the system, hence the $\mathrm{pH}$ value was usually in the range of 3-3.5. Pyrite ball milled for $24 \mathrm{~h}$ decolorizes RB in approximately 90 seconds, clearly faster than the decolourization by $10 \mathrm{~h}(20 \mathrm{~min}), 5 \mathrm{~h}(20$ 
$\min ), 1 \mathrm{~h}(60 \mathrm{~min})$, and hand-milled pyrite (40\% decolourization in $120 \mathrm{~min})$. As expected, the sample with the highest surface area catalysed the reaction more efficient. A sample with high surface area possesses more active sites for the ongoing reactions, where $\mathrm{Fe}^{2+}$-ions are formed and consequently more generation of hydroxyl radicals is possible. Our results confirm that the ball-milled pyrite has a powerful catalytic activity in the heterogeneous Fenton process even by using low concentrations of $\mathrm{FeS}_{2}(0.25 \mathrm{~g} / \mathrm{l})$ and $\mathrm{H}_{2} \mathrm{O}_{2}(9 \mathrm{mmol} / \mathrm{l}) .24 \mathrm{~h}$ ball-milled $\mathrm{FeS}_{2}$ possessed the best $\mathrm{RB}$ decolourization efficiency and was used in all further experiments in this study.

Table 1: Specific surface area of the prepared $\mathrm{FeS}_{2}$ samples.

\begin{tabular}{|l|c|c|c|c|c|}
\hline Milling time $(\mathrm{h})$ & 0 & 1 & 5 & 10 & 24 \\
\hline BET surface area $\left(\mathrm{m}^{2} / \mathrm{g}\right)$ & 0.1 & 2.7 & 5.6 & 7.3 & 17.1 \\
\hline
\end{tabular}

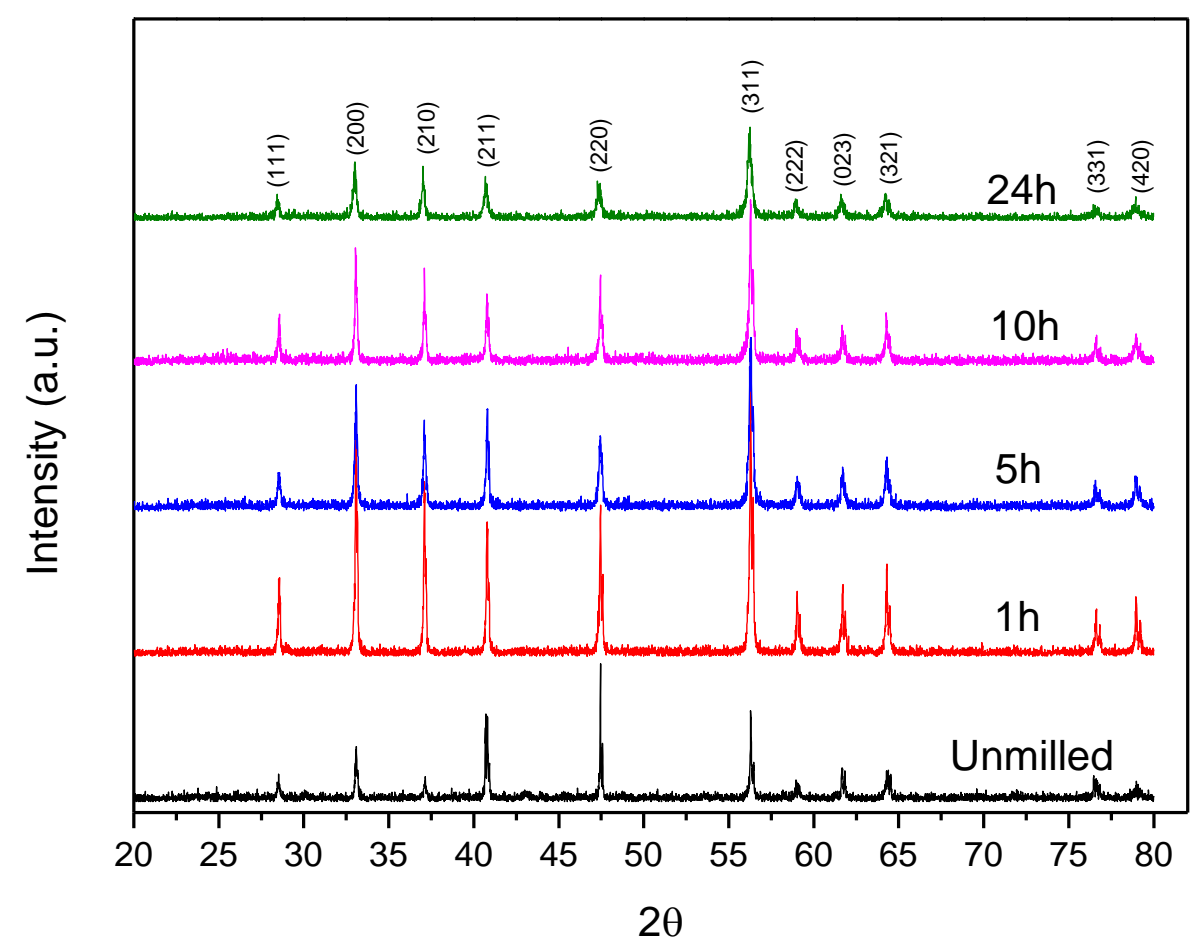

Fig. 1: XRD patterns of natural $\mathrm{FeS}_{2}$ before and after ball-milling for different times. 


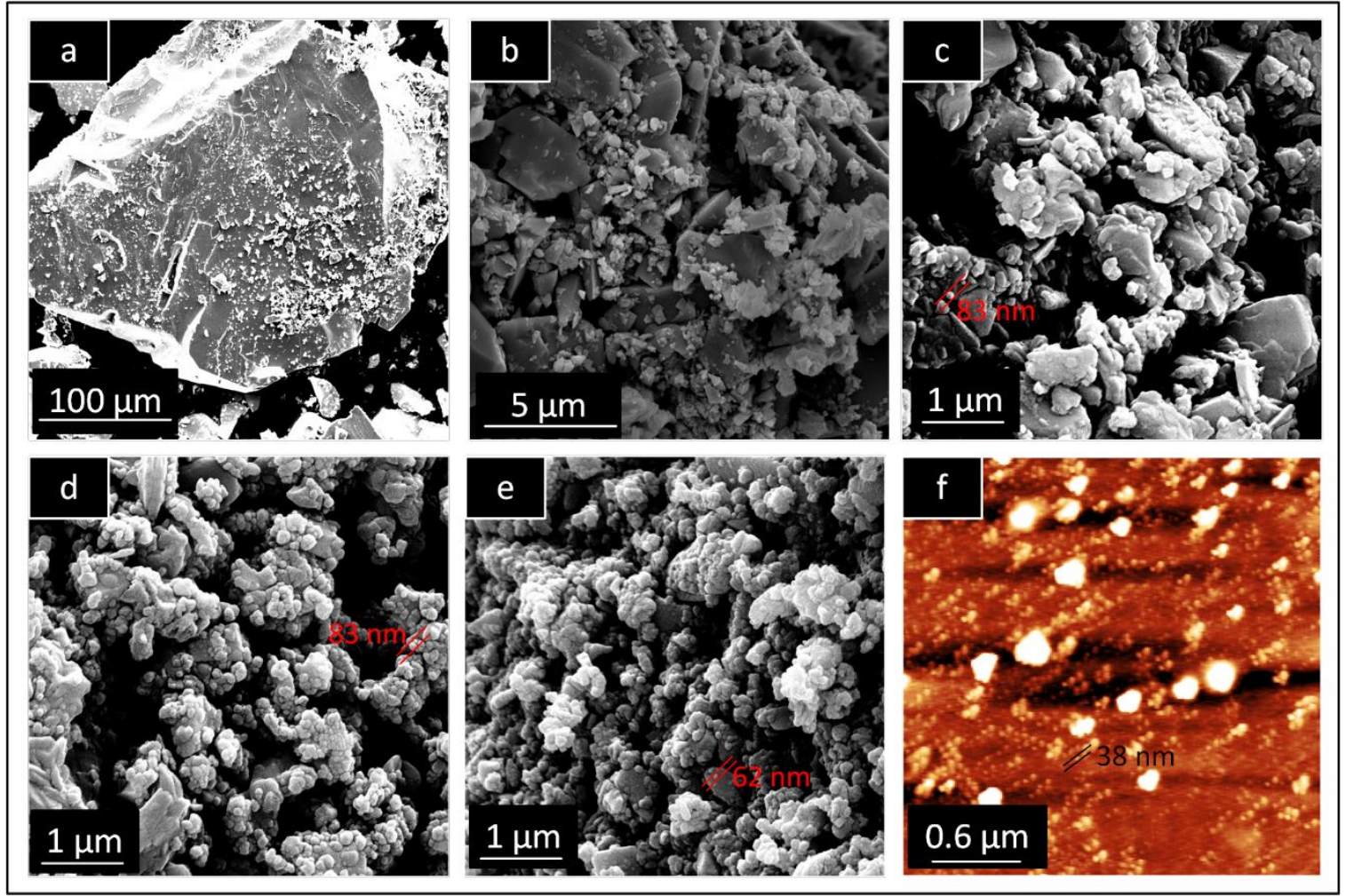

Fig. 2: SEM images of ball-milled $\mathrm{FeS}_{2}$ samples at $0 \mathrm{~h}(\mathrm{a}), 1 \mathrm{~h} \mathrm{(b),} 5 \mathrm{~h} \mathrm{(c),} \mathrm{10h} \mathrm{(d),} \mathrm{and} \mathrm{24h} \mathrm{(e).} \mathrm{AFM} \mathrm{for} 24 \mathrm{~h}$ sample (f).

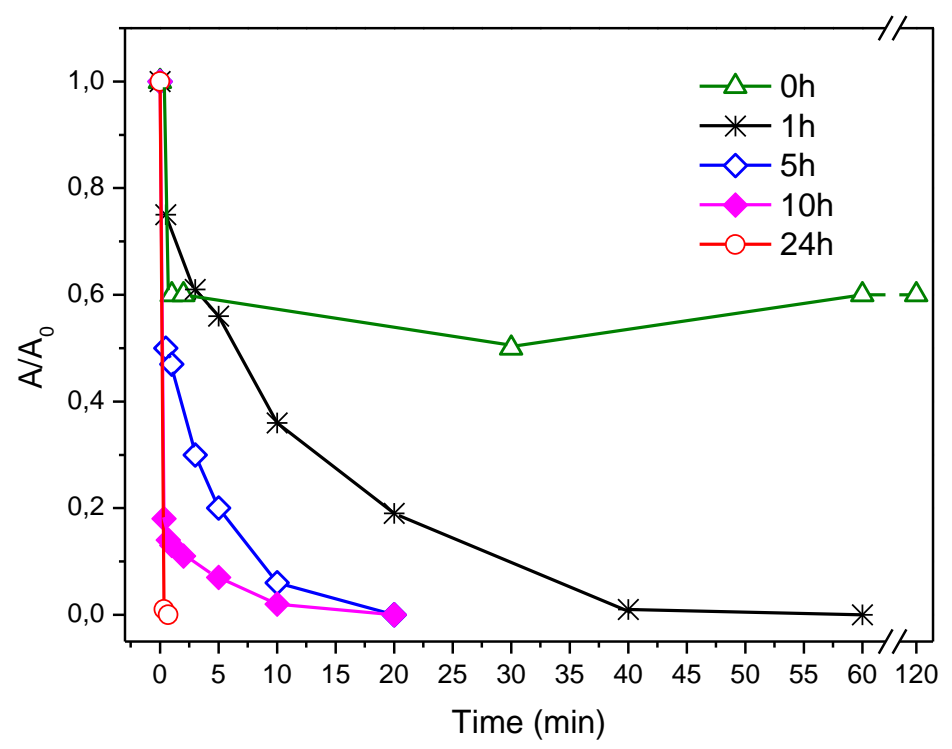

Fig. 3: Decolourization of RB using $\mathrm{FeS}_{2}$ ball-milled at different times. $\left[\mathrm{FeS}_{2}\right]=0.25 \mathrm{~g} / \mathrm{l},[\mathrm{RB}]=50 \mu \mathrm{M},\left[\mathrm{H}_{2} \mathrm{O}_{2}\right]=9 \mathrm{mM}, \mathrm{pH}=3.1 \pm 0.2 \mathrm{~A}$ : initial absorption, A: absorption at certain time.

\subsection{Effect of Inorganic lons}

Wastewater may contain a wide range of inorganic ions in different concentrations. These ions can affect the concentration of hydroxyl radicals during the Fenton reaction and retard or inhibit the degradation of the dye [13]. The effects of different concentrations of chloride $\left(\mathrm{Cl}^{-}\right)$, sulfate $\left(\mathrm{SO}_{4}^{2-}\right)$, hydrogen phosphate $\left(\mathrm{HPO}_{4}^{2-}\right)$ and nitrate $\left(\mathrm{NO}_{3}^{-}\right)$ions are 
summarized in Fig. 4 and Tab. 2. Sulphate- and chloride ions are able to react with the formed hydroxyl radicals as shown in reactions (5) - (10) $[14,15]$. They can form inorganic radicals such $\mathrm{SO}_{4}^{--}$and $\mathrm{Cl}_{2}^{-}$which are less reactive than the hydroxyl radicals [13]. Thereby, the amount of reactive hydroxyl radicals for the decomposition of RB becomes lower and the Fenton process is inhibited. Chloride- and sulphate ions also form stable complexes with $\mathrm{Fe}^{2+}$ and $\mathrm{Fe}^{3+}$ ions [16]. The formed complexes cannot catalyse $\mathrm{H}_{2} \mathrm{O}_{2}$ to produce hydroxyl radicals as efficiently as the free iron ion types, so that the amount of $\cdot \mathrm{OH}$ for the reaction is further reduced [17]. In this study, the inhibition effect of chloride ions is noticeable with increasing chloride ion concentration (Tab. 2). At a chloride concentration of $9 \mathrm{mM}$ a complete RB decolourization was obtained in $1.5 \mathrm{~min}$, similar than the reaction without chloride ions. At $30 \mathrm{mM}$ the decolourization time is prolonged until $5 \mathrm{~min}$ and at $200 \mathrm{mM}$ until $60 \mathrm{~min}$. In comparison to that, the addition of sulphate ions has less influence in the heterogeneous Fenton reaction, as can be seen in Tab. 2. Only at high sulphate ion concentration $(200 \mathrm{mM})$ is the decolourization time higher (5 $\mathrm{min}$ ) than the reaction without ion addition (1,5 min). Siedlecka at al. [16] mention following reasons for the lower inhibition effect of $\mathrm{SO}_{4}^{2-}$ in comparison to $\mathrm{Cl}^{-}$. The formed sulphate radicals $\left(\mathrm{SO}_{4}^{-}\right)$are more reactive than dichloride anion radicals $\left(\mathrm{Cl}_{2}^{-}\right)$so that they can take part in the reaction. Furthermore, the sulphate/Fe $\mathrm{Fe}^{2+}$ complex is more reactive towards $\mathrm{H}_{2} \mathrm{O}_{2}$ than $\mathrm{Fe}^{2+}$ alone. Therefore, the inhibitory potential of the sulphate ions is balanced.

The decolourization curves obtained with phosphate ions show that the heterogeneous Fenton reaction is very sensitive to these ions (Fig. 4). At pH 3, phosphate preliminarily exists in the form $\mathrm{H}_{2} \mathrm{PO}_{4}^{-}$which will react with $\mathrm{Fe}^{2+}$ and $\mathrm{Fe}^{3+}$ ions to form complex compounds $[17,18]$. Consequently, the concentration of the active dissolved iron remaining in the solution at high phosphate concentrations is low for the reaction with $\mathrm{H}_{2} \mathrm{O}_{2}$ and the Fenton reaction is inhibited. Additionally, other factors like the precipitation of iron-phosphate species on the catalyst surface $[13,19]$ and the adsorptions behaviour of the phosphate ions on the surface catalyst may also have a significant effect on the overall reaction rates. Yang et al. [19] demonstrated that phosphate ions could displace the adsorbed dye from the surface of $\mathrm{Fe}_{3} \mathrm{O}_{4}$ catalyst at neutral and acidic $\mathrm{pH}$, and inhibit its catalytic ability. Phosphate ions interact also with hydroxyl radicals (Eq. (11)), so that the amount of $\bullet \mathrm{OH}$ for the decomposition of the dye in the system is reduced. In our reactions, the decolourization of RB with phosphate concentration of $5 \mathrm{mM}$ and $9 \mathrm{mM}$ showed $22 \%$ and $19 \% \mathrm{RB}$ decolourization after $2 \mathrm{~h}$ reaction time, respectively. The low decolourization degrees indicates that the catalytic decomposition of $\mathrm{H}_{2} \mathrm{O}_{2}$ is strongly affected by these phosphate ion concentrations. On the contrary, at lower phosphate ion concentration $(0.5 \mathrm{mM})$ a complete RB decolourization could be reached in $40 \mathrm{~min}$.

Since nitrate ions do not form complexes with $\mathrm{Fe}^{2+}$ and $\mathrm{Fe}^{3+}$ ions and they will not react with hydroxyl radicals [18], they have only low influence on the heterogeneous Fenton reaction (Tab.2). Even at high nitrate concentration of $200 \mathrm{mM}$ the $\mathrm{RB}$ decolourization was completed in $3 \mathrm{~min}$. The sequence of inorganic ion inhibition effects according to our results was $\mathrm{HPO}_{4}^{2-}>\mathrm{Cl}^{-}>\mathrm{SO}_{4}^{2-} \approx \mathrm{NO}_{3}^{-}$.

$$
\begin{gathered}
\mathrm{Cl}^{-}+\cdot \mathrm{OH} \rightarrow[\mathrm{ClOH}]^{--} \\
{[\mathrm{CLOH}]^{-}+\mathrm{Cl}^{-} \rightarrow \mathrm{Cl}_{2}^{--}+\mathrm{OH}^{-}} \\
\mathrm{Cl}_{2}^{--}+\mathrm{H}_{2} \mathrm{O}_{2} \rightarrow \mathrm{HO}_{2}^{-}+2 \mathrm{Cl}^{-}+\mathrm{H}^{+} \\
\mathrm{Cl}_{2}^{--}+\mathrm{HO}_{2}^{-} \rightarrow 2 \mathrm{Cl}^{-}+\mathrm{H}^{+}+\mathrm{O}_{2} \\
\mathrm{H}_{2} \mathrm{SO}_{4}+\cdot \mathrm{OH} \rightarrow \mathrm{SO}_{4}^{--}+\mathrm{H}^{+}+\mathrm{H}_{2} \mathrm{O} \\
\mathrm{HSO}_{4}^{-}+\cdot \mathrm{OH} \rightarrow \mathrm{SO}_{4}^{--}+\mathrm{H}_{2} \mathrm{O} \\
\cdot \mathrm{OH}_{+} \mathrm{HPO}_{4}^{2-} \rightarrow \mathrm{HPO}_{4}^{--}+\mathrm{OH}^{-}
\end{gathered}
$$




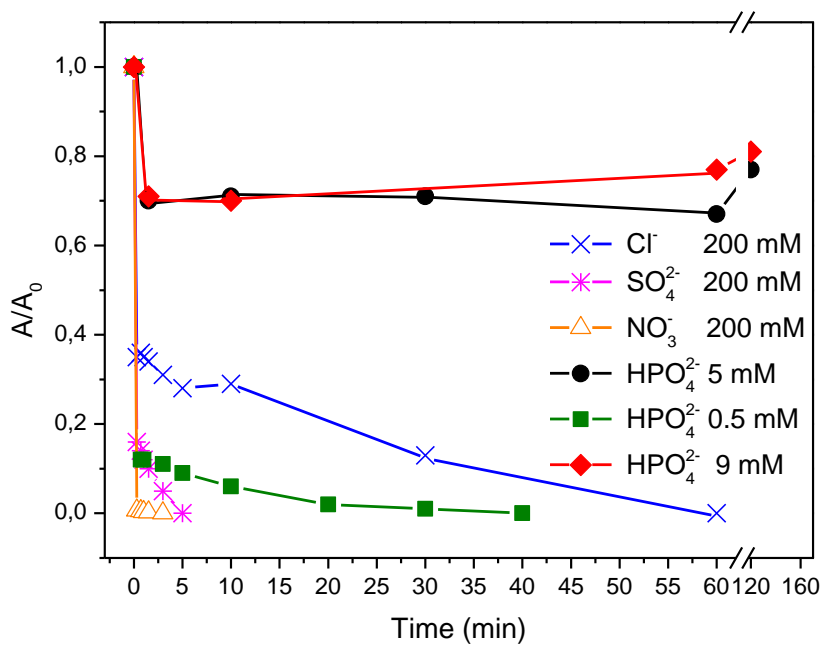

Fig. 4: Decolourization of RB in the presence of inorganic ions. $\left[\mathrm{FeS}_{2}\right]=0.25 \mathrm{~g} / \mathrm{l},[\mathrm{RB}]=50 \mu \mathrm{M},\left[\mathrm{H}_{2} \mathrm{O}_{2}\right]=9 \mathrm{mM}, \mathrm{pH}=3.1 \pm 0.2(\mathrm{except}$ for hydrogen phosphate at concentration of $9 \mathrm{mM}$ and $5 \mathrm{mM}, \mathrm{pH}=7 \pm 0.2)$. $\mathrm{A}_{0}$ : initial absorption, A: absorption at certain time.

Table 2: $\mathrm{RB}$ decolourization under different inorganic ion concentrations. $\left[\mathrm{FeS}_{2}\right]=0.25 \mathrm{~g} / \mathrm{l},[\mathrm{RB}]=50 \mu \mathrm{M},\left[\mathrm{H}_{2} \mathrm{O}_{2}\right]=9 \mathrm{mM}, \mathrm{pH}=3.1 \pm 0.2$.

\begin{tabular}{|c|c|c|c|}
\hline \multirow{2}{*}{$\begin{array}{c}\text { Concentration } \\
(\mathrm{mmol} / \mathrm{l})\end{array}$} & \multicolumn{3}{|c|}{ Time for complete RB decolourization } \\
& \multicolumn{3}{|c|}{$\left.\mathrm{Cl}^{-}\right)$} \\
\hline & $\mathrm{SO}_{4}^{2-}$ & $\mathrm{Cl}^{-}$ & $\mathrm{NO}_{3}^{-}$ \\
\hline 0 & 1.5 & 1.5 & 1.5 \\
\hline 9 & 1.5 & 1.5 & 1.5 \\
\hline 30 & 1.5 & 5 & 1.5 \\
\hline 200 & 5 & 60 & 3 \\
\hline
\end{tabular}

\section{Conclusion}

The low-cost, environmentally-friendly preparation of $\mathrm{FeS}_{2}$ nanoparticles via ball-milling and its testing as catalyst for the heterogeneous Fenton reaction were performed. The Rhodamine B dye was used as a model compound to monitor the catalyst performance under the presence of inorganic ions. The $\mathrm{FeS}_{2}$ sample with highly effective surface area showed the best efficiency as a catalyst. In the presence of sulphate- and nitrate ions the dye was completely decolorized in few minutes, while chloride ions affect the decolourization rate to a stronger degree. The strongest inhibition effect in the reaction was observed by phosphate ions. Our methodology offers a practical way of reducing costs for waste water remediation, due to the efficiency of the Fenton process catalysed by the $\mathrm{FeS}_{2}$ nanoparticles prepared in this work. The simple processing will permit this process to be applied in developing countries.

\section{Acknowledgements}

The authors are thankful to the "IWaTec project" which is funded by the German Academic Exchange Service (DAAD). We thank Dr. Vladimir Shvartsman for AFM measurements and Claudia Schenk for performing BET measurements.

\section{References}

[1] N. Wang, T. Zheng, G. Zhang, P. Wang, "A review on Fenton-like processes for organic wastewater treatment," $J$. Environ. Chem. Eng., vol. 4, pp. 762-787, 2016.

[2] Z.-H. Diao, J.-J. Liu, Y.-X. Hu, L.-J. Kong, D. Jiang, X.-R. Xu, "Comparative study of Rhodamine B degradation by the systems pyrite/ H2O2 and pyrite/persulfate: Reactivity, stability, products and Mechanism," Sep. Purif. Technol., vol. 184, pp. 374-383, 2017. 
[3] C. Gil-Lozano, E. Losa-Adams, A. F.-Davila and L. Gago-Duport, "Pyrite nanoparticles as a Fenton-like reagent for in situ remediation of organic pollutants," Beilstein J. Nanotechnol., vol. 5, pp. 855-864, 2014. doi:10.3762/bjnano.5.97.

[4] S. Bae, D. Kim, and W. Lee, "Degradation of diclofenac by pyrite catalyzed Fenton oxidation," Appl. Catal. B Environ., vol. 134-135, pp. 93-102, 2013.

[5] M. Becelic-Tomin, B. Dalmacija, L. Rajic, D. Tomasevic, D. Kerkez, M. Watson, and M. Prica, "Degradation of Anthraquinone Dye Reactive Blue 4 in Pyrite Ash Catalyzed Fenton Reaction," Sci. World J., 2014, doi:10.1155/2014/234654.

[6] Y. Zhang, K. Zhang, C. Dai, X. Zhou, and H. Si, "An enhanced Fenton reaction catalyzed by natural heterogeneous pyrite for nitrobenzene degradation in an aqueous solution," Chem. Eng. J., vol. 244, pp. 438-445, 2014.

[7] P. V. Nidheesh, H. Olvera-Vargas, N. Oturan, and M. A. Oturan, "Heterogeneous Electro-Fenton Process: Principles and Applications," The Handbook of Environmental Chemistry, 2017. doi: 10.1007/698_2017_72.

[8] H. Che, S. Bae, and W. Lee, "Degradation of trichloroethylene by Fenton reaction in pyrite suspension," J. Hazard. Mater., vol. 185, pp. 1355-1361, 2011.

[9] J. F. de Carvalho, S. N. de Medeiros, M. a. Morales, a. L. Dantas, and a. S. Carriço, "Synthesis of magnetite nanoparticles by high energy ball milling," Appl. Surf. Sci., vol. 275, pp. 84-87, 2013.

[10] X. Fu, Y. Hu, T. Zhang, and S. Chen, "The role of ball milled h-BN in the enhanced photocatalytic activity: A study based on the model of ZnO," Appl. Surf. Sci., vol. 280, pp. 828-835, 2013.

[11] P. Pourghahramani, B. N. Akhgar, "Characterization of structural changes of mechanically activated natural pyrite using XRD line profile analysis," Int. J. Miner. Process., vol. 134, pp. 23-28, 2015.

[12] S. Fathinia, M. Fathinia, A. A. Rahmani, and A. Khataee, "Preparation of natural pyrite nanoparticles by high energy planetary ball milling as a nanocatalyst for heterogeneous Fenton Process," Appl. Surf. Sci., vol. 327, pp. 190-200, 2015.

[13] J. De Laat, G. Truong Le, and B. Legube, "A comparative study of the effects of chloride, sulfate and nitrate ions on the rates of decomposition of $\mathrm{H} 2 \mathrm{O} 2$ and organic compounds by $\mathrm{Fe}(\mathrm{II}) / \mathrm{H} 2 \mathrm{O} 2$ and $\mathrm{Fe}(\mathrm{III}) / \mathrm{H} 2 \mathrm{O} 2$," Chemosphere, vol. 55, pp. 715-723, 2004.

[14] E. Lipczynska-Kochany, G. Sprah, and S. Harms, "Influence of some groundwater and surface waters constituents on the degradation of 4-Chlorophenol by the Fenton reaction," Chemosphere, vol. 30, pp. 9-20, 1995.

[15] J. De Laat and T. G. Le, "Effects of chloride ions on the iron(III)-catalyzed decomposition of hydrogen peroxide and on the efficiency of the Fenton-like oxidation process," Appl. Catal. B Environ., vol. 66, pp. 137-146, 2006.

[16] E. M. Siedlecka and P. Stepnowski, "Phenols Degradation by Fenton Reaction in the Presence of Chloride and Sulfate," Polish J. Environ. Stud., vol. 14, pp. 823-828, 2005.

[17] C. Ratanamaskul, S. Chintitanun, N. Masomboon, and M. C. Lu, "Inhibitor effect of inorganic ions on nitrobenzene oxidation by fluidized-bed Fenton process," J. Mol. Catal. A: Chem., vol. 331, pp. 101-105, 2010.

[18] M.-C. Lu, J.-N. Chen and C.-P. Chang, "Effect of inorganic ions on the oxidation of dichloruos insecticide with Fenton's reagent," Chemosphere, vol. 35, no. 10, pp. 2285-2293, 1997.

[19] X. Yang, J. He, Z. Sun, A. Holmgren and D. Wang, "Effect of phosphate on heterogeneous Fenton oxidation of catechol by nano-Fe3O4: Inhibitor or stabilizer?," J. Environ. Sci., vol. 39, pp. 69-76, 2016. 